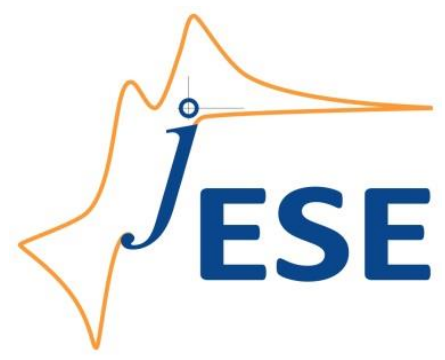

Open Access : : ISSN 1847-9286

www.jESE-online.org

Original scientific paper

\title{
Ellipsometric measurement of thickness of tin oxides grown by voltammetry in phosphate solution of $\mathrm{pH} \mathbf{8 . 7}$
}

Tiago Brandão Costa*, $₫$, Tania Maria Cavalcanti Nogueira*,**, Ladário da Silva*,***

*Programa de Pós-Graduação em Engenharia Metalúrgica (PPGEM), Escola de Engenharia Industrial Metalúrgica de Volta Redonda (EEIMVR), Universidade Federal Fluminense (UFF), 27255125 Volta Redonda, RJ, Brazil

**Departamento de Metalurgia, EEIMVR, UFF, 27255-125 Volta Redonda, RJ, Brazil

***Departamento de Física, Instituto de Ciências Exatas (ICEX), UFF, 27213-145 Volta Redonda, RJ, Brazil

Corresponding author: tiagobrandao@id.uff.br, Phone: +55-2421073731

Received: July 5, 2016; Revised: November 25, 2016; Accepted: November 28, 2016

\begin{abstract}
The voltammetry induced growth of tin oxides on tin in the buffer solution of $0.18 \mathrm{~mol} \mathrm{~L}^{-1}$ $\mathrm{Na}_{2} \mathrm{H}_{2} \mathrm{PO}_{4}$ and $0.18 \mathrm{~mol} \mathrm{~L}^{-1} \mathrm{KH}_{2} \mathrm{PO}_{4}(\mathrm{pH}$ 8.7) has been studied. Ex-situ ellipsometric measurements were made in an order to determine thicknesses of the grown oxides. From these results the film volume per charge unit, $\mathrm{V}_{f}$, was calculated for different charge densities of the film. This parameter was used to calculate the variable ionic resistivity of the film, $\rho_{f}$, considered by the Ohmic model for the case of voltammetric growth of oxides on metals having a previously existing continuous film. Tin oxide films grown at $2 \mathrm{mV} \mathrm{s} \mathrm{s}^{-1}$ showed to be less dense for values of charge density below $50 \mathrm{C} \mathrm{m}^{-2}$, having $\mathrm{V}_{f}$ near $5.7 \times 10^{-10} \mathrm{~m}^{3} \mathrm{C}^{-1}$. For higher values of charge density, tin oxide films become denser, having $V_{f}$ near $0.5 \times 10^{-10} \mathrm{~m}^{3} \mathrm{C}^{-1}$. The calculated values of the variable ionic resistivity of the film during voltammetric growth showed that $\rho_{f}$ passes through a minimum (justifying the maximum in current densities). This behavior was also found by other authors in the cases of $\mathrm{Zn}, \mathrm{Nb}, \mathrm{Ni}$ and galvanized steel sheets.
\end{abstract}

\section{Keywords}

Ellipsometry, Tin oxide, Ohmic model, Voltammetry, Variable ionic resistivity

\section{Introduction}

Active metals cannot be obtained without an initial thin film covering the surface, as have already been observed in the cases of $\mathrm{Cd}, \mathrm{Fe}, \mathrm{Ni}, \mathrm{Pb}, \mathrm{Sn}, \mathrm{Zn}$, valve metals, etc. For this reason, the studies of oxide growth on these metals are found very important. The growth of passivating films on metals 
under voltammetric conditions gives rise to peaks or polarographic waves in current/potential plots. This phenomenon is related to the active/passive transition, or growth of a continuous film on the metal surface.

Some electrochemical processes, such as electrodeposition of metallic ions [1-3] or growth of oxide on metals [4-8], can be considered as processes presenting ohmic behaviour. The Ohmic model developed by D'Alkaine [4] describes the relation between the current density and the film overpotential during the growth of passivating film under voltammetric conditions. This model considers that the relation between the electrode potential $E$ and overpotential at the metal/film/solution interface is given by:

$$
E=\eta_{\mathrm{m} / \mathrm{f}}+\eta_{\mathrm{f}}+E_{\mathrm{F}}
$$

In Eq. (1) $\eta_{m / f}$ is the overpotential at the metal/film interface, $\eta_{\mathrm{f}}$ is the overpotential across the film and $E_{\mathrm{F}}$ is the Flade potential. The overpotential at the film/solution interface is considered constant, i.e. independent of the current density, $j$.

The relation between current density $(j)$ and overpotential at the metal/film interface $\left(\eta_{m / f}\right)$ is given by the general expression:

$$
j=j_{\mathrm{m} / \mathrm{f}}^{0}\left[\exp \left(\alpha_{\mathrm{a}} n f \eta_{\mathrm{m} / \mathrm{f}}\right)-\exp \left\{-\left(\alpha_{\mathrm{c}} n f \eta_{\mathrm{m} / \mathrm{f}}\right)\right\}\right]
$$

In Eq. (2), $j_{\mathrm{m} / \mathrm{f}}^{0}$ is the exchange current density at zero $\eta_{\mathrm{m} / \mathrm{f}}, f$ is $\mathrm{F} / \mathrm{RT}, \alpha_{\mathrm{a}}$ and $\alpha_{\mathrm{c}}$ are anodic and cathodic transfer coefficients, while $n$ is charge of the metal ion in the film.

If $V_{\mathrm{f}}$ and $q_{\mathrm{f}}$ are respectively the volume per charge unit and the charge density related to the growing film, then the film thickness, $\ell$, is given by:

$$
\ell=V_{\mathrm{f}} q_{\mathrm{f}}
$$

The $q_{\mathrm{f}}$ value can be calculated as:

$$
q_{\mathrm{f}}=q_{\mathrm{volt}}+q_{\mathrm{o}}=\frac{1}{v} \int_{E_{\mathrm{i}}}^{E} j_{\mathrm{a}} \mathrm{d} E+q_{\mathrm{o}}
$$

In Eq. (4) $q_{0}$ is the charge density related to the amount of film initially present at the beginning of the voltammetric growth and $q_{\text {volt }}$ is the charge density related to the amount of film which has grown on the metal surface during the voltammetric experiment. $E_{\mathrm{i}}$ is the initial potential, $E$ is the potential attained and $j_{\mathrm{a}}$ is anodic component of the current density, taking into account Eq. (2).

For peak or plateau, transient conditions during voltammetric growth of a film on a metal surface, the following equation should be valid for any model:

$$
\eta_{\mathrm{f}, \mathrm{p}}=\frac{v}{j_{\mathrm{p}}} q_{\mathrm{f}, \mathrm{p}}
$$

In Eq. (5) $\eta_{\text {f.p }}$ is the overpotential across the film at the voltammetric peak, $v$ is the sweep rate, $j_{p}$ is the current density at the peak and $q_{\mathrm{f}, \mathrm{p}}$ is the peak or plateau charge density.

In the case of the Ohmic model, the relation between $j$ and $\eta_{\mathrm{f}}$, even at high fields, is given as:

$$
\eta_{\mathrm{f}}=V_{\mathrm{f}} \rho_{\mathrm{f}} q_{\mathrm{f}} j
$$

In Eq. (6), $\rho_{\mathrm{f}}$ is the average ionic specific resistivity of the film.

The Ohmic model takes into consideration that at the beginning of the scanning, the current density increases as a consequence of reduction of ionic resistivity of the film due to injection of defects in the film. Beyond the peak potential, it is possible to observe reduction of the current 
density, what is explained by ageing of the oxide film. This phenomenon turns the film more resistive to the passage of the current due to recombination of defects and to structural rearrangement [4]. This model, however, contains an intrinsic difficulty related to impossibility to determine $\rho_{\mathrm{f}}$ and $V_{\mathrm{f}}$ separately, using only electrochemical measurements. Despite this fact, many authors [4-8] applied the Ohmic model, considering the volume per charge unit $\left(V_{f}\right)$ as the constant equal to:

$$
V_{f}=\frac{M}{n F \delta}
$$

In Eq. (7) $M$ is the molar mass of the film, $\delta$ is density of the film, $n$ is the number of electrons and $F$ is the Faraday's constant.

The real values of $V_{f}$ during the voltammetric growth could only be determined by independent measurements of the film thickness. The aim of the present work is to study the voltammetric growth of tin oxides in a solution of phosphate ( $\mathrm{pH}$ 8.7) applying the Ohmic model. This solution was chosen in view of stability of the passive film on tin at this $\mathrm{pH}$, avoiding thus loss by chemical dissolution [9]. At the same time, there are some early studies concerning the passivating species under voltammetric growing conditions in the $\mathrm{pH}$ range 8-9 [10-14]. The thickness of the oxides grown by voltammetry will be determined by ex-situ ellipsometric measurements in an order to verify the intrinsic difficulty explained above. The ex-situ condition was first examined as a preliminary study in order to verify stability of the film in the atmosphere.

\section{Experimental}

\section{Electrochemical measurements}

The working electrode was made of a tin disc (99.999\% of purity) with the circular area of $50 \mu^{2}$. Before the experiments, the electrode surface was polished with 600-emery paper.

The electrochemical experiments were performed using the EG\&G Princeton Applied Research Model 273A potentiostat. Reagents PA and purified water (Millipore $Q$ system) were used. The electrolyte solution was $0.18 \mathrm{~mol} \mathrm{~L}^{-1} \mathrm{Na}_{2} \mathrm{H}_{2} \mathrm{PO}_{4}+0.18 \mathrm{~mol} \mathrm{~L}^{-1} \mathrm{KH}_{2} \mathrm{PO}_{4}, \mathrm{pH}$ 8.7. The experiments were carried out in a conventional three-compartment electrolysis cell, using a platinum wire as the counter and $\mathrm{Hg} / \mathrm{Hg}_{2} \mathrm{Cl}_{2} / \mathrm{KCl}(1 \mathrm{M})$ as the reference electrode, respectively.

All current and charge densities are given in terms of the geometric surface area of the analyzed samples.

Anodic voltammetries were carried out at sweep rates of 2, 5, 10, 20, 70, 100, 200, 300 and $400 \mathrm{mV} \mathrm{s}^{-1}$, always using the same sample. For this purpose, before each voltammetry experiment, the previously grown oxide film was reduced at constant cathodic potential equal to $-1.2 \mathrm{~V}$ during $600 \mathrm{~s}$. After this treatment, the obtained voltammograms were reproducible, indicating that surface roughness of samples was also reproducible.

\section{Ellipsometric measurements}

Ellipsometry [15] is a powerful and non-destructive technique, which allows one to access optical and dielectric properties of various materials in different forms (solids, liquids, and gases), as well as thicknesses of thin films [16-17]. It can also be used to monitor and analyze both in-situ [18-19] and ex-situ [20] experiments. Ellipsometry considers the change in the polarization state of incident light upon reflection from the studied material. Initially it accesses the ellipsometric parameters $\Psi$ and $\Delta$. These parameters are connected by the fundamental equation of ellipsometry [16]: 


$$
\frac{R_{\mathrm{p}}}{R_{\mathrm{s}}}=\tan (\psi) e^{\mathrm{i} \Delta}=f\left(n_{\mathrm{j}}, k_{j}, d_{\mathrm{j}}\right)
$$

In Eq. (8), $R_{\mathrm{p}}$ and $R_{\mathrm{s}}$ stand for the complex Fresnel reflection coefficients for $\mathrm{p}$ and $\mathrm{s}$ polarized light beams, respectively. $\Psi$ is the amplitude ratio for the reflected and polarized components ( $p$ and $s$ ), while $\Delta$ represents the phase difference between reflected $\mathrm{p}$ and $\mathrm{s}$ polarizations, created by reflection from the material. $n_{\mathrm{j}}, k_{\mathrm{j}}, d_{\mathrm{j}}$ are, respectively, the refractive index, the extinction coefficient and thickness of the $j^{\text {th }}$ layer of the material. The ex-situ ellipsometric measurements were made using a SEMILAB spectroscopic ellipsometer, model SOPRA GES 5E, equipped with a Xe lamp, over the spectrum range of $195-1,000 \mathrm{~nm}$. The investigation of the thickness of oxide films grown on the substrate of tin has been performed in air and at ambient temperature using the incident angle of $75^{\circ}$. As an indirect technique, it is necessary to model the material structure with its film layers in an order to obtain each layer film thickness. The thicknesses of the oxide films were obtained by analyzing the measured ellipsometric spectra through the Drude and Gauss model [16].

\section{Results and discussion}

As was explained before, in an order to obtain reproducibility, the voltammetric experiments were always carried out using the same sample. Before each voltammetry measurement, the oxide grown in the previous experiment was reduced at the constant cathodic potential during $600 \mathrm{~s}$. This cathodic treatment was sufficient to reproduce the initial roughness of the surface, which was verified by reproducible voltammograms obtained at the same sweep rate and shown in Fig. 1.

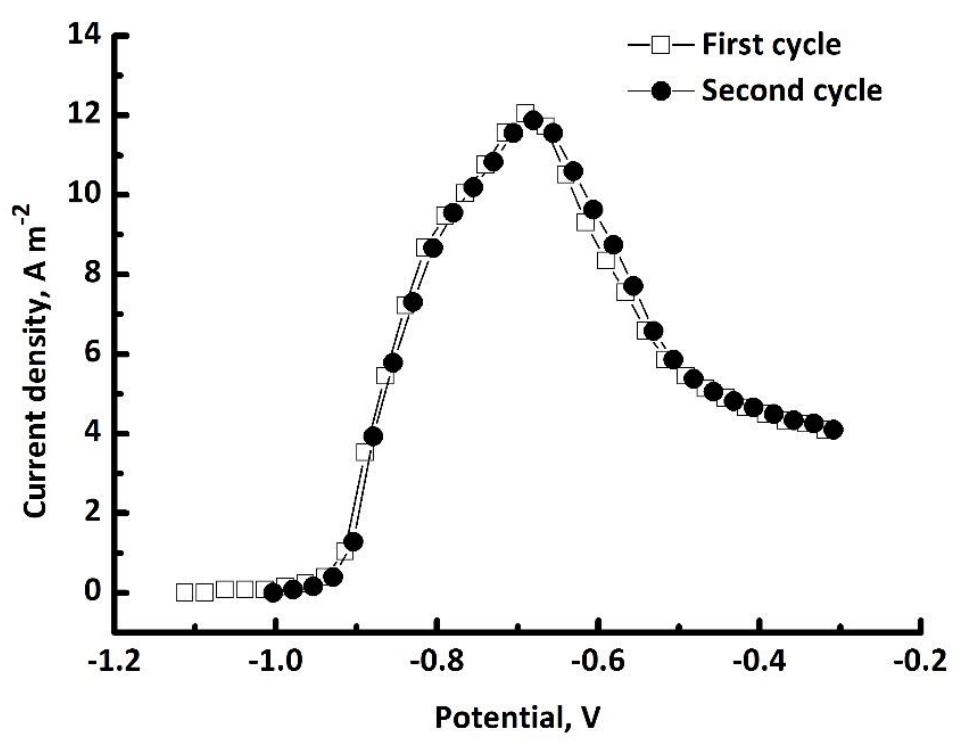

Fig. 1. First and second cycle at $50 \mathrm{mV} \mathrm{s}^{-1}$ in the phosphate solution $\mathrm{pH} 8.7$

The anodic voltammograms for tin oxide growth at different sweep rates are shown in Fig. 2. From these results, the overpotential values in the film at the peak condition $\left(\eta_{\mathrm{f}, \mathrm{p}}\right)$ were calculated using the Eq. (5). The value of $q_{0}$ in Eq. (4) was first considered equal to $0.0 \mathrm{C} \mathrm{m}^{-2}$. The curve $j$ vs. potential at the metal/film interface $\left(E_{\mathrm{m} / \mathrm{f}}\right)$, also shown in this Figure, is obtained after correction of the ohmic drop through the film at the peak potential $\left(E_{\mathrm{p}}-\eta_{\mathrm{f}, \mathrm{p}}\right)$. 


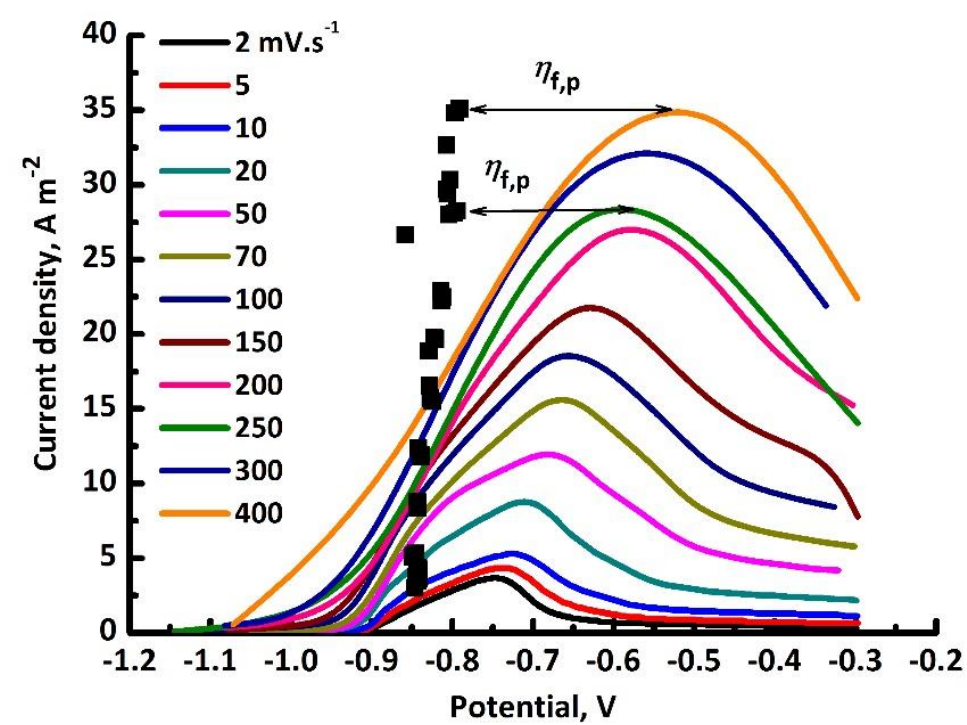

Fig. 2. Voltammetric growths of tin oxide film, together with the plot of the calculated $\mathrm{j} v \mathrm{vs}\left(\mathrm{E}_{p}-\eta_{f, p}\right)$ relation at the metal/film interface, considering $\mathrm{q}_{0}=0.0 \mathrm{C} \mathrm{m}^{-2}$.

The Tafel plot of the curve $j$ vs. $E_{\mathrm{m} / \mathrm{f}}$ in Fig. 2 is represented in Fig. 3.

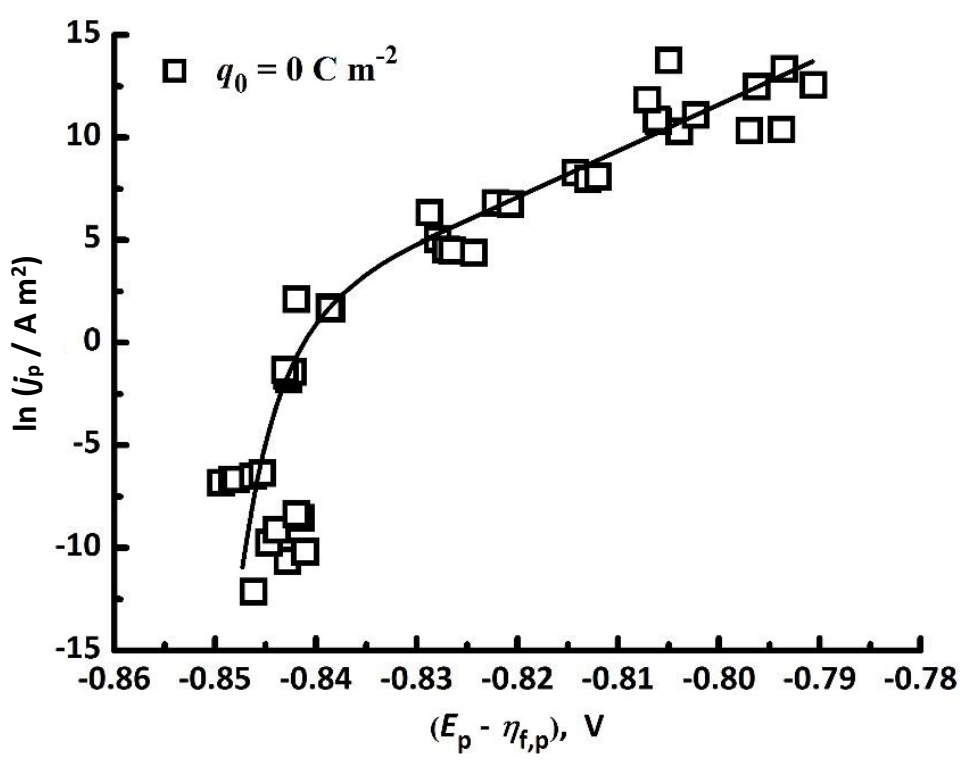

Fig. 3. Tafel plot at the tin/oxide interface.

In order to provide the best straight line region of the Tafel plot, the value of $q_{0}$ was taken equal to $2.5 \mathrm{C} \mathrm{m}^{-2}$. Fig. 4 presents the obtained result.

From these results, the obtained Tafel slope $\left(b_{a}\right)$ is equal to $41.995 \mathrm{mV} \mathrm{dec}^{-1}$. By using Eq. (9) [21]

$$
b_{\mathrm{a}}=\frac{\alpha_{\mathrm{m} / \mathrm{f}} n F}{R T}
$$

the transfer coefficients at the metal/film interface has been calculated as $\alpha_{\mathrm{m} / \mathrm{f}}=1.07$. 


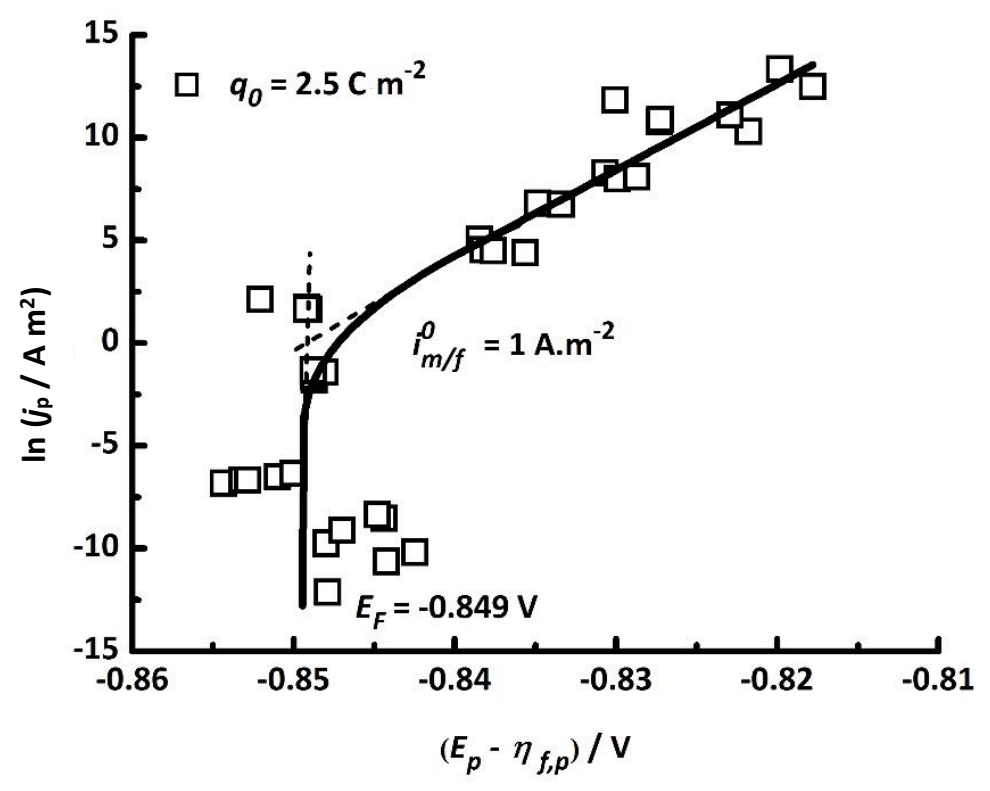

Fig. 4. Tafel plot at the tin/oxide interface, considering $\mathrm{q}_{0}=2.5 \mathrm{C} \mathrm{m}^{-2}$.

Fig. 5 presents the corrected curve $j v s . E_{m / f}$, which was obtained from the Tafel plot of Fig. 4. The anodic voltammograms are also shown in the same figure.

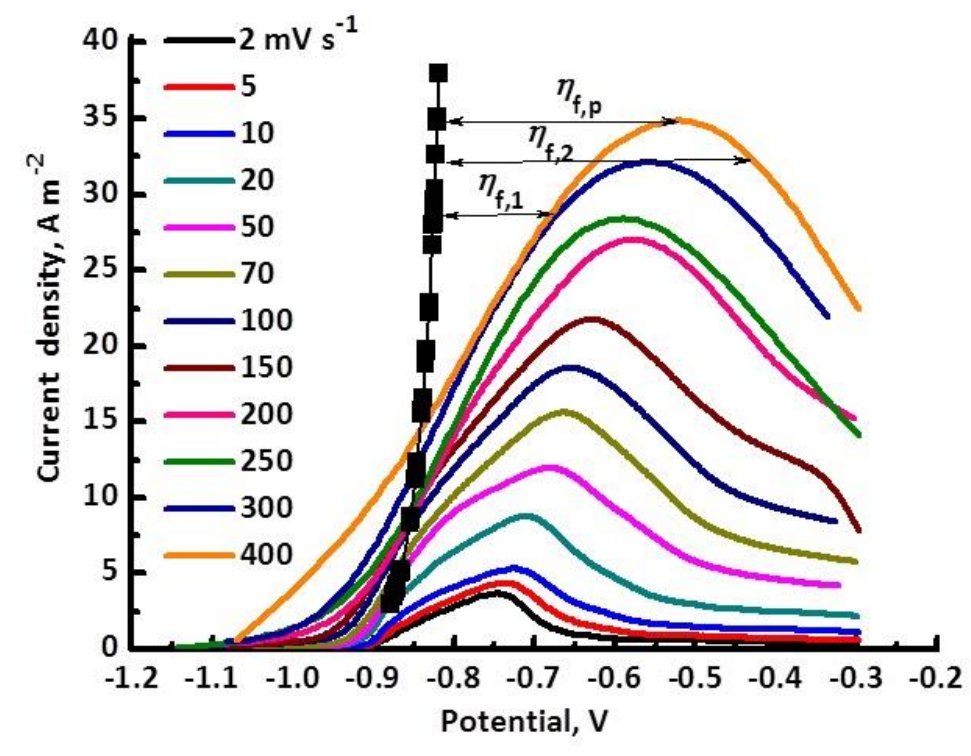

Fig. 5. Voltammetric growths of tin oxide film, together with the plot of the calculated $\mathrm{j} v \mathrm{vs}\left(\mathrm{E}-\mathrm{\eta}_{\mathrm{f}}\right)$ relation at the metal/film interface, considering $\mathrm{q}_{0}=2.5 \mathrm{C} \mathrm{m}^{-2}$ and Figure 4.

These results turn possible to determine the overpotential at the film $\left(\eta_{\mathrm{f}}\right)$ for any growing condition of the film beyond the peak condition. This can be done by calculating the difference of the potential in the voltammogram at any sweep rate and the potential in the curve $j v s . E_{\mathrm{m} / \mathrm{f}}$ for a given current density. This is shown in Fig. 5 for the voltammogram at $400 \mathrm{mV} \mathrm{s}^{-1}$.

Thus, by calculating, $\eta_{\mathrm{f}}$ values for each potential of each voltammetry experiment, it becomes possible to determine the ionic specific resistivity of the film $\left(\rho_{\mathrm{f}}\right)$ and its variation with $E$ and $v$ using Eq. (6). 
As was explained in the introduction of this work, the real values of $V_{f}$ during the voltammetric growth could only be determined by an independent way of measuring the thickness of the film according to the following equation:

$$
V_{f}=\frac{\ell A}{q_{f}}
$$

In Eq. (10), $\ell$ is thickness and $A$ is surface area the working electrode.

The thicknesses of oxides films grown at $2 \mathrm{mV} \mathrm{s}^{-1}$ were measured by ex-situ ellipsometry. This condition was chosen because using this sweep rate, higher thicknesses can be achieved. Fig. 6 presents the final potential $\left(E_{\mathrm{f}}\right)$ of each voltammetry experiment performed at $2 \mathrm{mV} \mathrm{s}^{-1}$.

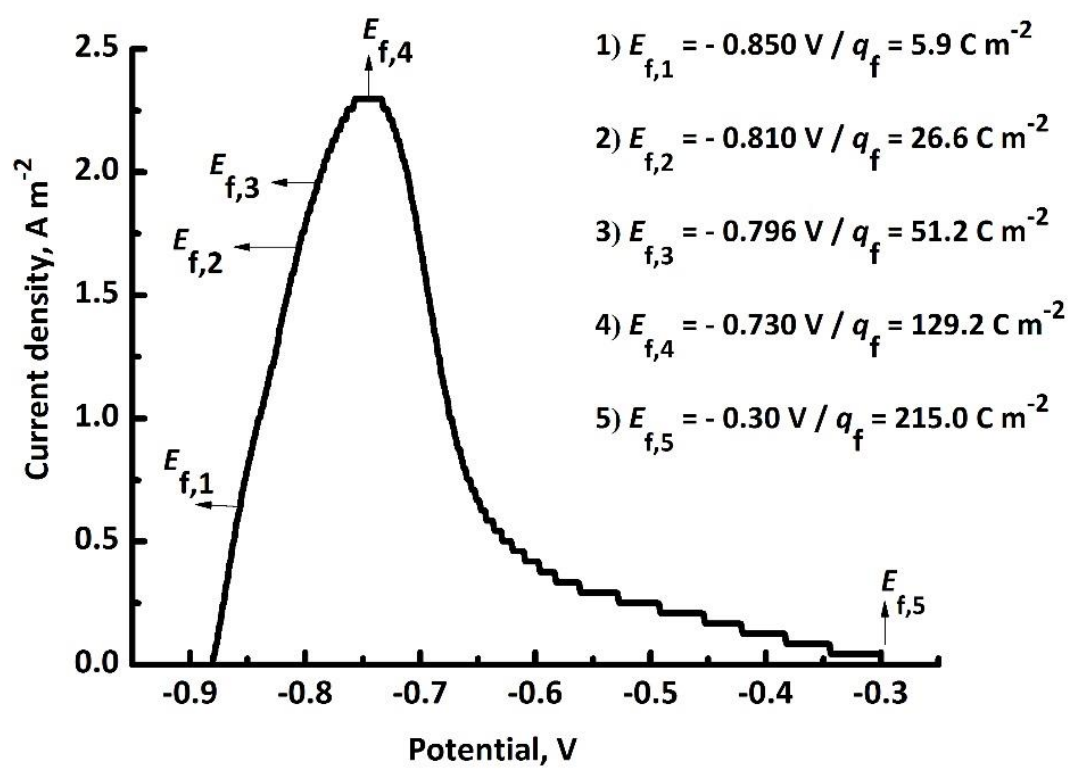

Fig. 6. Voltammetric growth of tin oxide films at $2 \mathrm{mV} \mathrm{s}^{-1}$, together with indication of the final potential, $\mathrm{E}_{f}$, and corresponding film charge density values.

As pointed out before, spectroscopic ellipsometer was used to obtain thin oxide film thicknesses for various charge densities. The proposed oxide layer structure is presented in Fig. 7. This oxide layer structure can be optically modelled using the both known refractive index $(n)$ and extinction coefficient ( $k$ ) of an available library ( $n k$ files) or dispersion relations for each of its layer constituents. Using the Drude and Gauss dispersion relations [16] for the film, the excellent fit was obtained between the used model and experimental data.

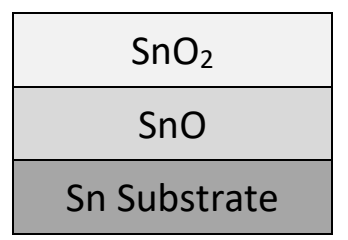

Fig. 7. Model for the tin oxide layer structure.

Fig. 8 exhibits typical results of fittings for measured and modelled values of $\tan \Psi$ and $\cos \Delta$ for charge densities equal to $5.9 \mathrm{C} \mathrm{m}^{-2}$ and $215.0 \mathrm{C} \mathrm{m}^{-2}$. 

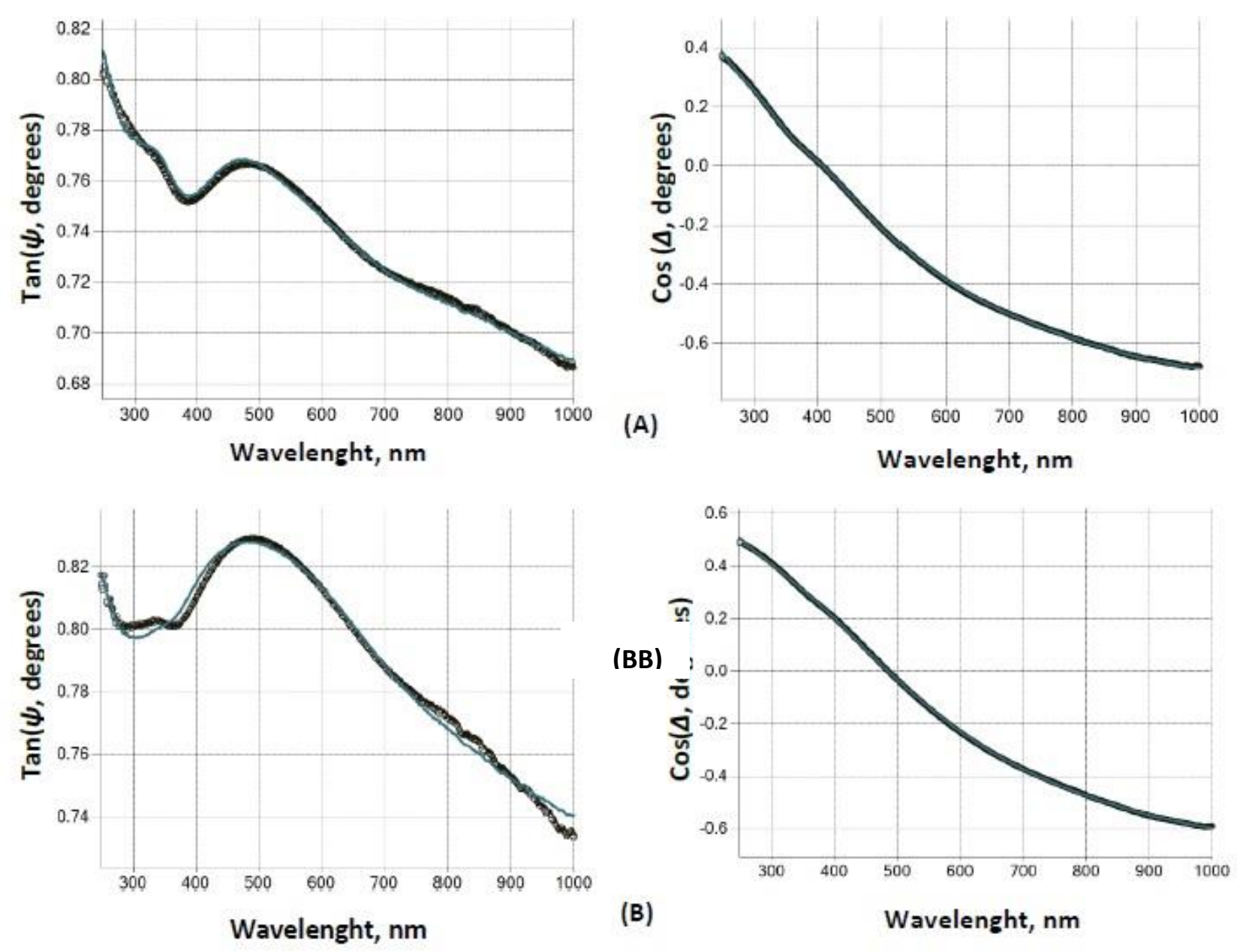

(B)

Wavelenght, $\mathrm{nm}$

Fig.8. Typical plots of measured (open circles) and modelled (blue line) of tan $(\Psi)$ and $\cos (\Delta)$ for tin oxide films and charge densities equal to: (A) $5.9 \mathrm{C} \mathrm{m}^{-2}$ and (B) $215.0 \mathrm{C} \mathrm{m}^{-2}$.

It is clear from the graphs in Fig. 8 that excellent fits $\left(R^{2}>0.99\right)$ were obtained, what make us confident to report the obtained thicknesses. The average thicknesses obtained considering eight measures at each charge density, are shown in Table 1 . Except thicknesses, $\ell$, in Table 1 , one can also see values of the final potential, $E_{\mathrm{f}}$, charge density of the film, $q_{\mathrm{f}}$, and statistical results $\left(\mathrm{R}^{2}\right.$, as well as standard deviations of the average thickness values, $\sigma$ ). Data in Table 1 clearly show that for greater $E_{\mathrm{f}}$ and $q_{\mathrm{f}}$, greater average film thickness is obtained.

Table 1: Final potentials, charge densities, thicknesses, average thicknesses and statistical results of calculations

\begin{tabular}{|c|c|c|c|c|c|c|c|c|c|c|c|c|}
\hline$E_{\mathrm{F}} / \mathrm{V}$ & $q_{\mathrm{f}} / \mathrm{C} \mathrm{m}^{-2}$ & & & & $e /$ & $\mathrm{nm}$ & & & & $R^{2}$ & Average thicknesses, $\mathrm{nm}$ & $\sigma$ \\
\hline-0.850 & 5.9 & 3.8 & 3.8 & 3.5 & 3.5 & 3.0 & 3.1 & 3.0 & 3.3 & 0.994 & 3.37 & 0.307 \\
\hline-0.810 & 26.6 & 4.3 & 3.8 & 4.6 & 4.5 & 3.9 & 4.0 & 3.8 & 3.7 & 0.990 & 4.10 & 0.323 \\
\hline-0.796 & 51.2 & 4.3 & 4.5 & 4.6 & 4.1 & 3.9 & 4.3 & 4.1 & 4.5 & 0.975 & 4.29 & 0.226 \\
\hline-0.730 & 129.2 & 9.4 & 9.0 & 9.3 & 8.9 & 9.4 & 9.0 & 9.3 & 9.1 & 0.981 & 9.20 & 0.185 \\
\hline-0.300 & 215.0 & 10.7 & 11.6 & 10.3 & 11.3 & 10.3 & 11.0 & 12.2 & 10.8 & 0.995 & 11.00 & 0.612 \\
\hline 0.100 & 268.1 & 13.7 & 12.5 & 13.2 & 12.9 & 12.4 & 11.2 & 11.8 & 11.5 & 0.987 & 12.40 & 0.806 \\
\hline
\end{tabular}

In the preliminary experiment, a sample was left in the atmosphere during $24 \mathrm{~h}$ in order to measure the stabilized oxide film thickness and the resulting value was $2.0 \mathrm{~nm}$. In Table 1, however, one can notice that the lowest average thickness for the film grown in conditions of voltammetric 
experiments was $3.37 \mathrm{~nm}$. This suggests that here obtained results are significantly influenced by the voltammetric way of film growth.

Using the experimentally found values of average thicknesses, Eq. (10) was applied and $V_{f}$ was determined for the values of charge density of voltammetry grown films at $2 \mathrm{mV} \mathrm{s}^{-1}$. The results are shown in Table 2 and Fig. 9.

Table 2: Film volume per charge unit obtained from the thicknesses measurements of tin oxide films for different charge densities.

\begin{tabular}{ccc}
\hline $\boldsymbol{q}_{\mathrm{f}} / \mathbf{C ~}^{-\mathbf{2}}$ & $\boldsymbol{\ell} / \mathbf{n m}$ & $\boldsymbol{V}_{\mathrm{f}} / \mathbf{1 0}^{-\mathbf{1 0}} \mathbf{m}^{\mathbf{3}} \mathrm{C}^{-\mathbf{1}}$ \\
\hline 5.9 & 3.37 & 5.70 \\
\hline 26.6 & 4.10 & 1.54 \\
\hline 51.2 & 4.29 & 0.84 \\
\hline 129.2 & 9.20 & 0.71 \\
\hline 215.0 & 11.00 & 0.50 \\
\hline 268.1 & 12.40 & 0.46 \\
\hline
\end{tabular}

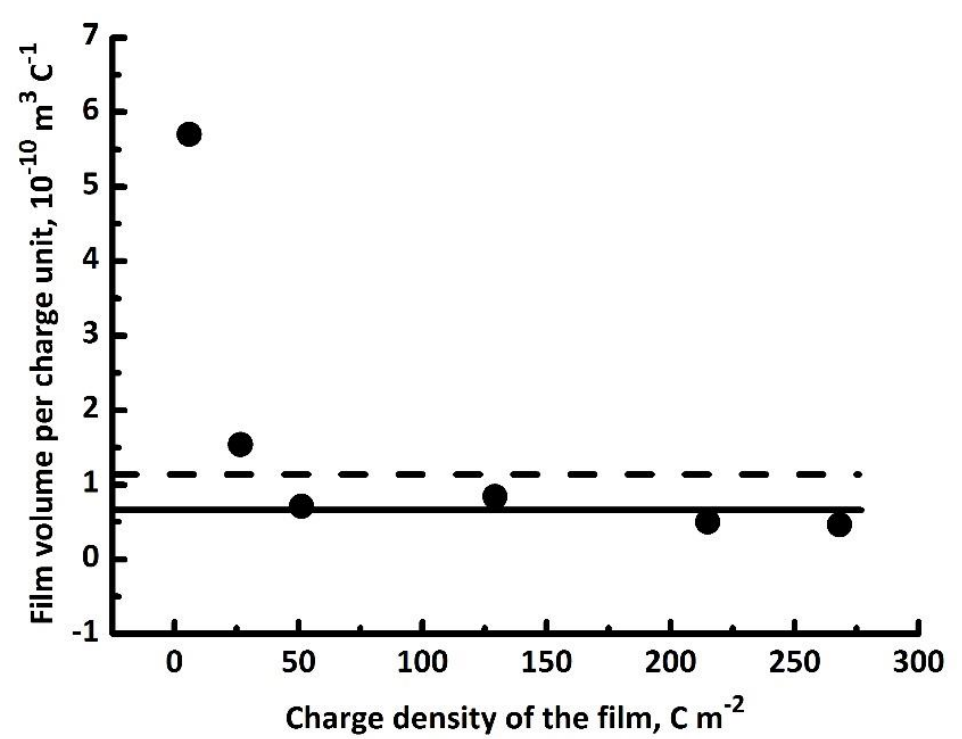

Fig. 9. Film volume per charge unit determined for different values of charge densities. $(\bullet)$ Experimental $\mathrm{V}_{f}$, (---) $\mathrm{V}_{f}=1.08 \times 10^{-10} \mathrm{~m}^{3} \mathrm{C}^{-1}$ (considering $\mathrm{SnO}$ ) and $(-) \mathrm{V}_{f}=0.568 \times 10^{-10} \mathrm{~m}^{3} \mathrm{C}^{-1}$ (considering $\mathrm{SnO}_{2}$ )

Data in Table 2 and Fig. 9 show that the values of $V_{\mathrm{f}}$ significantly decrease until $50 \mathrm{C} \mathrm{m}^{-2}$ of charge density of the film is achieved. This suggested that the film is less dense for lower values of charge density and becomes denser as the thickness increases [22]. Besides that, the value of $V_{f}$ for charge density of $26.6 \mathrm{C} \mathrm{m}^{-2}$ is close to the value of $V_{f}$ calculated by Eq. (7), considering a film of SnO $\left(1.08 \times 10^{-10} \mathrm{~m}^{3} \mathrm{C}^{-1}\right)$. For higher values of charge density, the value of $V_{f}$ turns close to the value of $V_{\mathrm{f}}$ calculated considering a film of $\mathrm{SnO}_{2}\left(0.568 \times 10^{-10} \mathrm{~m}^{3} \mathrm{C}^{-1}\right)$. These results suggest that changes in the composition of the film are taking place as the potential turns more anodic. In fact, Duc and Tissot [23], studying the oxidation of tin in neutral phosphate solution, suggested that $\mathrm{Sn}(\mathrm{OH})_{2}$ or $\mathrm{SnO}$ and $\mathrm{Sn}(\mathrm{OH})_{4}$ or $\mathrm{SnO}_{2}$ are present on the electrode surface at the beginning of polarization. At more anodic potentials only stannic species are formed. Electrochemical behavior of tin has also been studied in aqueous alkaline solutions [10-11,14,24-29]. The authors considered that primary passivation occurs due to formation of $\mathrm{Sn}(\mathrm{OH})_{2}$ or $\mathrm{SnO}$ film by a dissolution-precipitation 
mechanism. The final passivation is characterized by a continuous film of $\mathrm{Sn}(\mathrm{OH})_{4}$ [10]. Then, more stables species like $\mathrm{SnO}_{2}$ or $\mathrm{SnO}_{2} \cdot \mathrm{H}_{2} \mathrm{O}$ can be formed from dehydration of this last film [9]. Some authors have suggested a duplex film [28], consisting of $5 \mathrm{SnO} 2 \mathrm{H}_{2} \mathrm{O}$ and $\mathrm{SnO}_{2} \cdot \mathrm{H}_{2} \mathrm{O}$ [29]. All these results emphasized importance of ellipsometric measurements in order to determine the thickness of the films. In fact, the exact composition of the film cannot be determined electrochemically.

By introducing experimentally determined $V_{f}$ values into Eq. (6) the values of $\rho_{f}$ can be calculated. Fig. 10 illustrates the results obtained using the values of charge density in Table 2 for the case of the voltammetry experiment at $2 \mathrm{mV} \mathrm{s}^{-1}$.

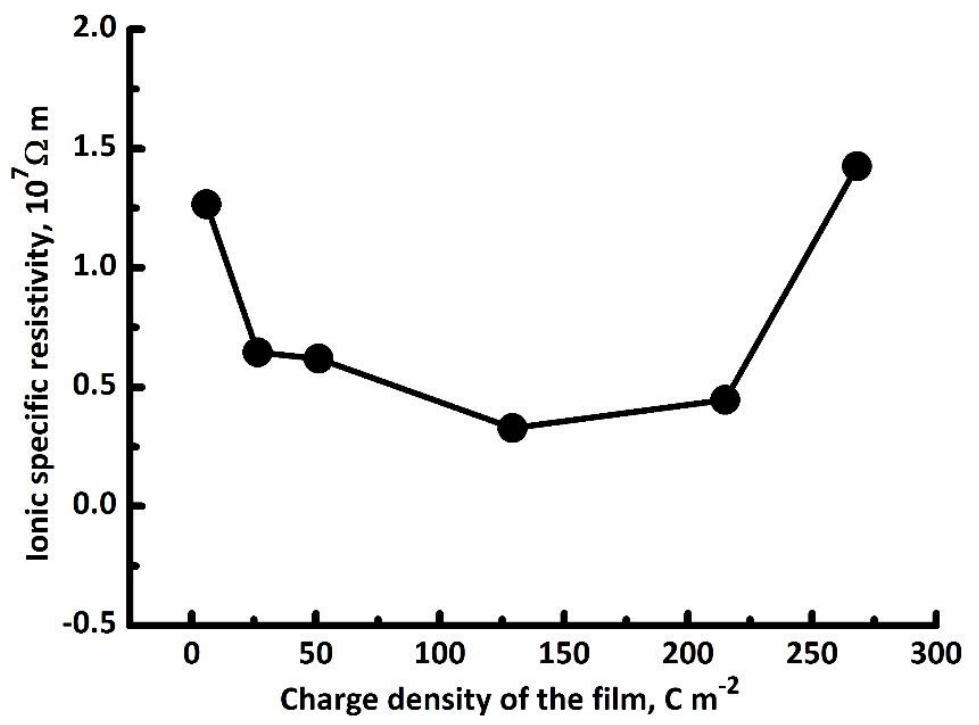

Fig. 10. Ionic specific resistivity vs. charge density of the film for sweep rate equal to $2 \mathrm{mV} \mathrm{s}^{-1}$.

As can be observed in Fig. 10, $\rho_{f}$ passes through a minimum (justifying the maximum in current densities). This behavior was also found by other authors for $\mathrm{Zn}, \mathrm{Nb}, \mathrm{Ni}$ and galvanized steel sheets [4-8]. According to the theory, this happens because the passage of current in the film of initial thickness $\left(q_{0}\right)$ generates injection of specific defects, what resulted in decrease of $\rho_{\mathrm{f}}$ (inversely proportional to concentration of defects) [4-8]. Increase of recombining specific defects (interstitial and cationic vacancies) in the film ends up by generating the recombination reaction (interstitial cation + cationic vacancy $\rightarrow$ cationic net), and making $\rho_{\mathrm{f}}$ to increase again [4-8].

\section{Conclusions}

The ex-situ ellipsometric measurements of the thickness of tin oxides film grown by voltammetry experiments at $2 \mathrm{mV} \mathrm{s}^{-1}$ in the studied solution showed that the film is less dense for values of charge density below $50 \mathrm{C} \mathrm{m}^{-2}$ having $V_{f}$ near $5.7 \times 10^{-10} \mathrm{~m}^{3} \mathrm{C}^{-1}$. For higher values of charge density, the film becomes denser having $V_{\mathrm{f}}$ near $0.5 \times 10^{-10} \mathrm{~m}^{3} \mathrm{C}^{-1}$.

From the experimentally determined values of $V_{f}$, the values of the variable ionic resistivity of the film during the voltammetric growth, $\rho_{\mathrm{f}}$, were calculated. The behavior of $\rho_{\mathrm{f}}$ versus the charge density of the film was like that found by other authors in the cases of $\mathrm{Zn}, \mathrm{Nb}, \mathrm{Ni}$ and galvanized steel sheets.

Acknowledgements: The author (Tiago Brandão Costa) is grateful to CAPES for his Doctor fellowship. The authors are grateful to Programa de Pós-Graduação em Engenharia Metalúrgica (PPGEM), Escola de Engenharia Industrial Metalúrgica de Volta Redonda (EEIMVR), Universidade Federal 
Fluminense (UFF) for the opportunity of realizing this work, making the Laboratory of Electrochemical available.

\section{Notation}

A electrode surface area, $\mathrm{m}^{2}$

$b_{\text {a }}$ Tafel slope

E potential, $\mathrm{V}$

$E_{\mathrm{F}} \quad$ Flade potential, $\mathrm{V}$

$E_{\mathrm{m} / \mathrm{f}}$ potential at the metal/film interface, $\mathrm{V}$

$F \quad$ Faraday's constant, $\mathrm{C} \mathrm{mol}^{-1}$

j current density, $\mathrm{A} \mathrm{m}^{-2}$

$j_{p} \quad$ current density at the voltammetric peak, $\mathrm{A} \mathrm{m}^{-2}$

$j_{m / f}^{0}$ exchange current density at zero $\eta_{\mathrm{m} / \mathrm{f}}, \mathrm{A} \mathrm{m}^{-2}$

$\ell \quad$ thickness of oxide layer, $\mathrm{m}$

$M$ molar mass of the film, $\mathrm{kg}$

$n \quad$ number of electrons

$q_{\mathrm{f}}$ charge density of the film, $\mathrm{C} \mathrm{m}^{-2}$

$q_{0}$ charge density related to the amount of film initially present, at the beginning of the voltammetric growth on the metal surface, $\mathrm{C} \mathrm{m}^{-2}$

$q_{\text {volt }}$ charge density related to the amount of film which has grown during voltammetric experiment, $\mathrm{C} \mathrm{cm}^{-2}$

$q_{\mathrm{f}, \mathrm{p}}$ peak or plateau charge density, $\mathrm{C} \mathrm{cm}^{-2}$

$R \quad$ gas constant, $8.314 \mathrm{~J} / \mathrm{mol} \mathrm{K}$

SE spectroscopic ellipsometry

$T$ temperature, $\mathrm{K}$

$V_{\mathrm{f}} \quad$ volume per charge unit, $\mathrm{m}^{3} \mathrm{C}^{-1}$

$\alpha_{a}$ anodic transfer coefficient

$\alpha_{c}$ cathodic transfer coefficient

$\delta$ density of the film, $\mathrm{kg} \mathrm{m}^{-3}$

$\eta_{\mathrm{m} / \mathrm{f}}$ overpotential at the metal/film interface

$\eta_{\text {f.p }}$ overpotential across the film at the voltammetric peak

$\eta_{\mathrm{f}}$ overpotential across the film

$v$ sweep rate, $\mathrm{V} \mathrm{s}^{-1}$

$\rho_{\mathrm{f}} \quad$ ionic specific resistivity of the film, $\Omega \mathrm{m}$

\section{References}

[1] A. S. Gliozzi, A. L. Alexe-lonescu, G. Barbero, Phys. Lett. A. 379 (2015) 2657-2660.

[2] A. L. Alexe-Ionescu, G. Barbero, S. Bianco, G. Cicero, C.F. Pirri, J. Electroanal. Chem. 669 (2012) 21-27.

[3] G. Barbero, P. Batallioto, A. M. Figueiredo Neto, J. Appl. Phys. 101 (2007) 054102(1)054102(5).

[4] C. V. D'Alkaine, P. C. Tulio, M. A. C. Berton, Electrochim. Acta 49 (2004) 1989-1997.

[5] C. V. D'Alkaine, L. M. N. Souza, F. C. Nart, Corr. Sci. 34 (1993) 129-149.

[6] C. V. D’Alkaine, M. N. Boucherit, J. Electrochem. Soc. 10 (1997) 3331-3336.

[7] C. V. D'Alkaine, M. A. Santanna, J. Electroanal. Chem. 457 (1998) 13-21.

[8] T. B. Costa, C. V. D'Alkaine, T. M. C. Nogueira, $67^{\text {th }}$ ABM International Congress, Voltammetric growth of $\mathrm{ZnO}$ on galvanized steel sheets containing $\mathrm{Sb}$ or $\mathrm{Pb}$, Rio de Janeiro, Rio de Janeiro, 2012, p. 3162. 
[9] M. Pourbaix, Atlas of Electrochemical Equilibria in Aqueous Solution, Pergamon, Oxford, 1966.

[10] S. D. Kapusta, N. Hackerman, Electrochim. Acta 25 (1980) 1625-1639.

[11] M. Metikos-Hukovic, A. Resetic, V. Gvozdic, Electrochim. Acta 40 (1995) 1777-1779.

[12] T. Hurlen, Electrochem. Acta 39 (1994) 1359-1364.

[13] S. A. M. Refaey, Electrochim. Acta 41 (1996) 2545-2549.

[14] V. Brunetti, M. L. Teijelo, J. Electroanal. Chem. 613 (2008) 9-15.

[15] H. Fujiwara, Spectroscopic Ellipsometry: Principles and Applications. John Wiley \& Sons Ltd, Tokyo, Japan, 2003.

[16] D. E. Aspnes, Thin Solid Films 571(3) (2014) 334-344.

[17] K. Vedam, Thin Solid Films 313-314 (1998) 1 - 9.

[18] L. Arsov, I. Mickova, J. Electrochem. Sci. Eng. 5(4) (2015) 221-230.

[19] I. Arsova, Lj. Arsov, N. Hebestreit, A. Anders, W. Plieth, J. Solid State Electrochem. 11 (2007) 209-214.

[20] L. F. N. Guedes et al. J. Solid State Electrochem 20 (2016) 2517-2523.

[21] A. J. Bard and L. R. Faulkner, Electrochemical Methods Fundamentals and Applications, John Wiley \& Sons, New York, United States, 2001.

[22] K. Wasa, M. Kitabatake, H. Adachi, Thin films Materials Technology: sputtering of compound Materials, William Andrew, New York, United States, 2004, p.28.

[23] H. Do Duc, P. Tissot, Corros. Sci. 19 (1979) 179-190.

[24] C. A. Gervasi, P. E. Alvarez, Corros. Sci. 47 (2005) 69 -78.

[25] S. D. Kapusta, N. Hackerman, Electrochim. Acta 25 (1980) 949-955.

[26] S. D. Kapusta, N. Hackerman, Electrochim. Acta 25 (1980) 1001-1006.

[27] S. D. Kapusta, N. Hackerman, Electrochim. Acta 25 (1982) 1886-1889.

[28] M. Metikos-Hukovic, M. Seruga, F. Ferina, Ber. Bunsenges, Phys. Chem. 96 (1992) 799-805.

[29] A. Ammar, S. Darwish, M. W. Khalil, S. El-Taher, Electrochim. Acta 33 (1988) 231-238.

2016 by the authors; licensee IAPC, Zagreb, Croatia. This article is an open-access article distributed under the terms and conditions of the Creative Commons Attribution license (http://creativecommons.org/licenses/by/4.0/) 